\title{
eCommons@AKU
}

Department of Paediatrics and Child Health

Division of Woman and Child Health

September 2018

\section{Maternal predictors of intrauterine growth retardation}

Nadia Mohammad

Aga Khan University, nadia.mohammad@aku.edu

Arjumand Sohaila

Aga Khan University, arjumand.sohaila@aku.edu

Unaib Rabbani

Aga Khan University, unaib.rabbani@aku.edu

Sufian Ahmed

Shakeel Ahmed

Aga Khan University, shakeel.ahmed@aku.edu

See next page for additional authors

Follow this and additional works at: https://ecommons.aku.edu/

pakistan_fhs_mc_women_childhealth_paediatr

Part of the Pediatrics Commons

\section{Recommended Citation}

Mohammad, N., Sohaila, A., Rabbani, U., Ahmed, S., Ahmed, S., Ali, S. R. (2018). Maternal predictors of intrauterine growth retardation. Journal of the College of Physicians and Surgeons Pakistan, 28(9), 681-685.

Available at: https://ecommons.aku.edu/pakistan_fhs_mc_women_childhealth_paediatr/702 
Authors

Nadia Mohammad, Arjumand Sohaila, Unaib Rabbani, Sufian Ahmed, Shakeel Ahmed, and Syed Rehan Ali 


\title{
Maternal Predictors of Intrauterine Growth Retardation
}

\author{
Nadia Mohammad', Arjumand Sohaila1, Unaib Rabbani1, Sufian Ahmed ${ }^{2}$, Shakeel Ahmed ${ }^{1,3}$ and Syed Rehan Ali1
}

\begin{abstract}
Objective: To identify maternal factors associated with intrauterine growth restriction (IUGR).

Study Design: A case-control study.

Place and Duration of Study: Neonatal Unit of The Aga Khan Hospital for Women (AKHW), Karimabad, from January 2014 to December 2015.

Methodology: Cases were IUGR live born babies $(n=90)$, while control were appropriate-for-gestational age (AGA) babies $(n=180)$. Information recorded in pre-designed proforma included gestational age and birth weight of baby, demographics of mothers, pregnancy related medical and obstetric complications. Data were analysed through SPSS- 19. Multivariable logistic regression was used to determine the maternal factors associated with the intrauterine growth restriction.

Results: Maternal factors associated with IUGR after adjusting for confounders in the multivariable model included younger age $(\mathrm{OR}=0.9, \mathrm{Cl}=0.8-0.9)$, poor gestational weight gain $(\mathrm{OR}=3.0, \mathrm{Cl}=1.6-6.1)$ and history of previous abortion $(\mathrm{OR}=3.06, \mathrm{Cl}=1.1-8.0)$. Significant interaction was found between pregnancy-induced hypertension $(\mathrm{PIH})$ and parity of mother, primary-para mother with PIH having an increased risk for IUGR babies $(\mathrm{OR}=10.1, \mathrm{Cl}=1.0-23.2)$.

Conclusion: Young age, primigravida status, low gestational weight gain, previous history of abortion, PIH and GDM have strong association with IUGR; hence, special consideration is essential to overcome these issues in order to improve maternal and neonatal health.
\end{abstract}

Key Words: Intrauterine growth retardation. Gestational diabetes. Low gestational weight gain.

\section{INTRODUCTION}

Intrauterine growth retardation (IUGR) represents the second leading cause of perinatal morbidity and mortality in non-anomalous fetuses, after prematurity.1,2 IUGR refers to the fetus whose birth weight less than 10th centile for gestational age and displays signs of chronic hypoxia or malnutrition. ${ }^{3}$

IUGR is observed in $23.8 \%$ of newborns around the world; and significant global burden approximate $75 \%$ of IUGR neonates are contributed by the Asian continent. 4 In Pakistan, the incidence of IUGR is around $25 \%,{ }^{5}$ more than the WHO criteria for triggering a public health action. It is mainly due to a pathologic slow-down in the fetal growth pace, resulting in a fetus that is unable to reach its growth potential.

There are multiple factors associated with high incidence of IUGR and there is a strong positive correlation exists between fetal, placental and maternal factors, but maternal factors per se significant cause of IUGR. ${ }^{4}$ Poor

1 Department of Pediatrics, The Aga Khan University Hospital, Karachi.

2 Student, University of Karachi, Karachi.

3 Department of Pediatrics, Bahria University Medical \& Dental College, Karachi.

Correspondence: Dr. Shakeel Ahmed, Consultant Pediatrician, Department of Pediatrics and Child Health, The Aga Khan

University Hospital, Stadium Road, Karachi.

E-mail: shakeel.ahmed@aku.edu

Received: September 21, 2017; Accepted: June 29, 2018. maternal nutrition, poor maternal weight gain, maternal anemia, inadequate prenatal care, short interpregnancy interval, pregnancy-induced hypertension $(\mathrm{PIH})$, gestational diabetes (GDM), maternal infection, and maternal chronic illness are major maternal risk factors. ${ }^{6}$ Healthy dietary habit, avoidance of unhealthy lifestyles, receiving proper prenatal care, and close antenatal surveillance of high risk pregnancy may help in declining the risk for IUGR.

The objective of this study was to identify maternal factors associated with IUGR. A comprehensive understanding of these factors will help in providing early interventions to improve the perinatal outcome due to IUGR.

\section{METHODOLOGY}

This study was carried as a case-control study in the Neonatal Unit of The Aga Khan Hospital for Women (AKHW), Karimabad, Karachi, from January 2014 to December 2015. Babies born after 32 weeks gestation, without lethal congenital anomalies were included. Cases were IUGR neonates (defined as babies with abnormal Doppler ultrasound and weight less than 10 percentile for gestational age); and controls were appropriate for gestational age (AGA) neonates with normal Doppler ultrasound as per American College of Obstetricians and Gynecologists (ACOG) definition. The case-control ratio was kept at 1:2. Cases and controls were selected retrospectively from hospital records during the study period. Data was retrieved using ICD discharge codes, and medical records were reviewed in detail.

A pre-designed proforma was filled by reviewing the clinical notes which entailed information about basic 
demographic information like, gestational age, birth weight, gender, mode of delivery, Apgar score, maternal age, maternal weight, maternal illness during pregnancy, antenatal care (ANC) visit, inter-pregnancy interval, previous IUGR births, amniotic fluid index, and umbilical artery blood flow. The study was carried out after obtaining approval from the Institutional Ethical Review Committee.

Gestational age (recorded as completed weeks) was calculated from maternal last menstrual period (LMP) and was categorised as preterm less than 37 weeks and term as 37 weeks or above.

As per routine practice, birth anthropometries were measured by staff nurse in labour room or operation theatre by using standardised equipment. Weight was measured without clothes using standard weighing balance in kilogram $(\mathrm{kg})$ and length by a non-stretchable measuring tape in centimeter $(\mathrm{cm})$. The calibration of the weighing scale was checked regularly before each measurement in order to avoid error. All measurements were recorded in a structured proforma during file review and plotted on specific WHO growth charts (Fenton growth chart), and percentiles was noted. Maternal age at the time of delivery was recorded. Maternal weight and height at the time of initial visit was used to calculate body mass index (BMI) for mother. Gestational weight gain was calculated by difference in the maternal weight at the time of $1 \mathrm{st}$ visit during $1 \mathrm{st}$ trimester and at the time of delivery and categorised into poor weight gain $<10 \mathrm{~kg}$ and good weight gain $>10 \mathrm{~kg}$.

Pregnancy-induced medical disorders and obstetrical complications like placenta previa, abruptio placentae, anemia, PIH; and GDM was also obtained. Interpregnancy interval was estimated by the number of months between the conception of current pregnancy and the previous delivery, abortion or stillbirth.

The statistical analysis was computed by using the SPSS version 19. Mean \pm SD was calculated for continuous variables; while for qualitative variables frequencies and percentages were analysed. Crosstabulation was done to see the independent variables across the categories of outcome (IUGR and AGA). Chisquare test was applied for categorical variables and independent sample t-test was applied for measureable variables, and $p<0.05$ considered as significant. Multivariable logistic regression was performed to analyse the association between maternal factors and intrauterine growth restriction. Multivariable analysis was calculated for the variables found to be stastically significant or with $p$-value $\leq 0.20$ in univariate analysis.

\section{RESULTS}

In this study, 90 cases and 180 controls were recruited for analysis. Table I shows the distribution of various characteristics between cases and controls. Mothers of cases were younger $26.7 \pm 4.4$ years compared to mothers of controls $28.0 \pm 4.4$ years $(p=0.025)$. There was low weight gain during pregnancy among cases as $80 \%(n=72)$ had poor weight gain compared to $60 \%$ $(n=108)$ among controls. Among cases, 58\% $(n=52)$ were primi compared to $66 \%(n=119)$ among controls; and this was not found to be significantly different. Significantly, higher proportion of cases had history of previous abortion $21 \%(n=19)$ compared to controls $8 \%$ $(n=15)$. A higher proportion of cases had history of GDM $16.7 \%(n=15)$ compared to about $4 \%(n=7)$ in controls. Similarly, history of PIH was positive more in cases $13.3 \%(n=12)$ than controls $4 \%(n=7)$.

Logistic regression analysis showed that increasing age of mother was protective against IUGR adjusted OR 0.93 (95\% Cl: 0.88-0.99, p= 0.006). On the other hand, women who had poor weight gain during pregnancy

Table I: Comparison of characteristics of cases and controls.

\begin{tabular}{|c|c|c|c|}
\hline Variable & Case 90 & Control 180 & $\mathrm{p}$-value \\
\hline \multicolumn{4}{|l|}{ Gender } \\
\hline Male & $49(54.4)$ & $93(51.7)$ & \\
\hline Female & $41(45.6)$ & $87(48.3)$ & 0.667 \\
\hline Age of mothera & $26.7( \pm 4.4)$ & $28.0( \pm 4.4)$ & 0.025 \\
\hline \multicolumn{4}{|l|}{ BMI of mother } \\
\hline Normal & $43(47.8)$ & $82(45.6)$ & 0.926 \\
\hline Underweight & $12(13.3)$ & $23(12.8)$ & \\
\hline Overweight & $22(24.4)$ & $51(28.3)$ & \\
\hline Obese & $13(14.4)$ & $24(13.3)$ & \\
\hline \multicolumn{4}{|c|}{ Weight gain during pregnancy } \\
\hline Poor & $72(80)$ & $108(60)$ & \\
\hline Good & $18(20)$ & $72(40)$ & 0.001 \\
\hline \multicolumn{4}{|l|}{ Parity } \\
\hline Primi & $52(57.8)$ & $119(66.1)$ & \\
\hline Multi & $38(42.2)$ & $61(33.9)$ & 0.180 \\
\hline \multicolumn{4}{|l|}{ Previous abortion } \\
\hline Yes & $19(21.1)$ & $15(8.3)$ & \\
\hline No & $71(78.9)$ & $165(91.7)$ & 0.003 \\
\hline \multicolumn{4}{|l|}{ Anemia during pregnancy } \\
\hline Yes & $25(27.8)$ & $48(26.7)$ & \\
\hline No & $65(72.2)$ & $132(73.3)$ & 0.846 \\
\hline Variable & Case & Control & $\mathrm{p}$-value \\
\hline \multicolumn{4}{|l|}{ GDM } \\
\hline Yes & $15(16.7)$ & $7(3.9)$ & \\
\hline No & 75 (83.3) & $173(96.1)$ & $<0.001$ \\
\hline \multicolumn{4}{|l|}{ PIH } \\
\hline Yes & $12(13.3)$ & $7(3.9)$ & \\
\hline No & $78(86.7)$ & $173(96.1)$ & 0.004 \\
\hline \multicolumn{4}{|l|}{ Multiple gestation } \\
\hline Yes & $4(4.4)$ & $17(9.4)$ & \\
\hline No & $86(95.6)$ & $163(90.6)$ & 0.0148 \\
\hline \multicolumn{4}{|l|}{ Antenatal visit } \\
\hline$<2$ & $2(2.2)$ & $4(2.2)$ & \\
\hline $2-4$ & $16(17.8)$ & $19(10.6)$ & \\
\hline$>4$ & $72(80)$ & $157(87.2)$ & 0.249 \\
\hline Weight of mothera & $57.9( \pm 12.4)$ & $57.8( \pm 12.5)$ & 0.923 \\
\hline Height of mothera & $155( \pm 5.3)$ & $154.3( \pm 5.6)$ & 0.811 \\
\hline Interpregnancy intervala & $0.95( \pm 1.86)$ & $0.59( \pm 1.12)$ & 0.099 \\
\hline
\end{tabular}


Table II: Regression analysis of factors associated with intrauterine growth retardation.

\begin{tabular}{|c|c|c|c|c|}
\hline Variables & Unadjusted OR $(95 \% \mathrm{Cl})$ & $p$-value & Adjusted OR $(95 \% \mathrm{Cl})$ & $\mathrm{p}$-value \\
\hline \multicolumn{5}{|l|}{ Gender } \\
\hline Male & 1 & 0.667 & -- & \\
\hline Female & $0.89(0.58-1.49)$ & 0.026 & $0.93(0.85-0.97)$ & 0.006 \\
\hline Age $^{a}$ & $0.93(0.88-0.99)$ & & & \\
\hline Weighta & $1.0(0.98-1.02)$ & 0.922 & -- & \\
\hline Heighta & $1.03(0.98-1.08)$ & 0.259 & -- & \\
\hline \multicolumn{5}{|l|}{ BMI } \\
\hline Normal & 1 & & & \\
\hline Under & $1.0(0.45-2.19)$ & 0.990 & -- & \\
\hline Over & $0.82(0.44-1.53)$ & 0.538 & & \\
\hline Obese & $1.03(0.48-2.23)$ & 0.934 & & \\
\hline \multicolumn{5}{|l|}{ Weight gain } \\
\hline Good & 1 & & 1 & \\
\hline Poor & $2.67(1.47-4.84)$ & 0.001 & $3.09(1.65-6.15)$ & 0.001 \\
\hline \multicolumn{5}{|l|}{ Parity } \\
\hline Primary & 1 & & 1 & \\
\hline Multi & $1.43(0.85-2.40)$ & 0.181 & $1.33(0.66-2.72)$ & 0.427 \\
\hline \multicolumn{5}{|c|}{ Previous abortion } \\
\hline No & 1 & & 1 & \\
\hline Yes & $2.94(1.41-6.12)$ & 0.004 & $3.06(1.17-8.0)$ & 0.023 \\
\hline Variables & Unadjusted OR $(95 \% \mathrm{Cl})$ & $p$-value & Adjusted OR (95\% Cl) & $p$-value \\
\hline \multicolumn{5}{|l|}{ Anemia } \\
\hline No & 1 & & & \\
\hline Yes & $1.06(0.60-1.87)$ & 0.846 & -- & \\
\hline \multicolumn{5}{|l|}{ GDM } \\
\hline No & 1 & & 1 & \\
\hline Yes & $4.94(1.93-12.62)$ & 0.001 & $3.34(1.22-9.17)$ & 0.019 \\
\hline \multicolumn{5}{|l|}{ PIH } \\
\hline No & 1 & & 1 & 0.036 \\
\hline Yes & $3.80(1.448-10.02)$ & 0.007 & $3.10(1.08-8.94)$ & \\
\hline \multicolumn{5}{|c|}{ Multiple gestation } \\
\hline No & 1 & & 1 & \\
\hline Yes & $0.45(0.14-1.37)$ & 0.158 & $0.44(0.13-1.49)$ & 0.188 \\
\hline \multicolumn{5}{|c|}{ Antenatal visits } \\
\hline$>4$ & 1 & & & \\
\hline $2-4$ & $1.84(0.89-3.78)$ & 0.099 & & \\
\hline 1 & $1.09(0.20-6.09)$ & 0.922 & -- & \\
\hline \multicolumn{5}{|c|}{ Pregnancy interval (years) } \\
\hline 2 or more & 1 & & & \\
\hline Less than 2 & $0.82(0.43-1.60)$ & 0.56 & -- & \\
\hline
\end{tabular}

were at almost three times higher risk of IUGR adjusted OR 3.09 (95\% Cl: 1.65-6.15, p=0.001). History of previous abortion was associated with three times higher risk of IUGR compared to those without history of previous abortion adjusted OR 3.06 (95\% Cl: 1.17-8.0, p=0.023). There was more than three times higher risk adjusted OR 3.34 (95\% Cl: 1.22-9.17, $p=0.019)$ of IUGR among women with history of GDM. History of PIH was also found to be associated with significant risk of IUGR adjusted OR 3.1 (95\% Cl: 1.08-8.94, p=0.036). Multiple regression analysis is shown in Table II.

\section{DISCUSSION}

Obstetric and maternal risk factors for IUGR are well described in many studies. We found significant differences for maternal predictors as age, parity, weight gain, previous history of abortion, GDM and $\mathrm{PIH}$ between the IUGR and AGA after adjusting for probable confounding.

Maternal age is one of the important risk factors associated with birth weight of the neonate. The relationship between maternal age and IUGR was found significant when compared between cases and control. Maternal age less than 27 years was one of the predictors in this study, similar findings were observed in studies conducted by Jamal et al. and Taj,7,8 while in comparison with Odibo et al. study, who observed a strong association between increasing maternal age and risk of IUGR.9

Primigravida mothers are at risk to deliver IUGR babies. It has been evident that the birth weight increases with 
parity (up to 4-5 births) but declines afterward.10 Proportion of primigravida was high in this study; similar findings were also reported by different studies from Pakistan and India. 8,11,12

Inadequate nutrition is not uncommon factor of impaired fetal growth. Here, maternal weight and height on first visit was used to calculate BMI. Studies from neighbouring countries have shown that BMI, prepregnancy body weight, and weight gain during pregnancy had significant effect on birth weight. ${ }^{13,14}$ There was no significant association between maternal nutritional status (BMI) and the IUGR births, in contrast with results observed in study by Taj et al. and Acharya. 8,12

Weight gain during pregnancy has strong, positive impact on fetal growth suggesting that energy balance is an important determinant of birth outcomes. ${ }^{15}$ Low weight gain reflects deficiency of calorie and micronutrients, which are essential for fetal growth. ${ }^{16}$ In this study, poor gestational weight gain was also a significant factor of IUGR, mothers with poor weight gain during pregnancy had three times risk of delivering babies with IUGR as compared to mothers with good gestational weight gain. These findings were consistent with different Indian studies which showed poor gestational weight gain, for even short-term, places the fetus at risk for IUGR. ${ }^{17-20}$ Improving maternal weight prior to conception and pregnancy weight gain are possible strategies to improve birth weight.

Anemia is a common problem in pregnant women in developing countries. In this study, anemia in pregnancy $\mathrm{Hb}<10 \mathrm{gm} \%$ ) was not significantly associated with IUGR. It was found $27.8 \%$ of mothers with anemia $(p=0.8)$. This is in contrast with studies at Goa and Karnataka, which have shown $49 \%(p<0.001)$ and $76 \%$ $(p=0.01)$ of mothers had anemia, respectively. 11,12

Maternal diabetes causes long term changes in placenta and may cause fetal growth restriction 16, GDM is found in $10 \%$ of women with IUGR. ${ }^{21}$ This study has shown strong association between IUGR and GDM, there was more than three times higher risk of IUGR among mothers with GDM; this finding is not consistent with study by Taj. 8

Hypertensive conditions are responsible for one-third of all fetal growth retardation. $22 \mathrm{PIH}$ is a frequent cause of placental insufficiency. In this study, PIH was associated with higher risk of IUGR with adjusted odds ratio 3.1 $(p=0.036)$. This is consistent with study by Taj, Thompson et al. and Burke.8,23,24 Burke reported preeclampsia with a combined odds ratio of $5.4(p<0.001),{ }^{24}$ while the incidence of IUGR among preeclamptic women was $22.2 \%$, found in study by Viller. 25

The present results also suggest negative effect of previous history of abortion on fetal growth. Similar finding was observed in study by Motghare. However, no such relation was seen in study by Aghamolaei et al.26

Although sample size calculation was not done prior to the study; however, post-hoc power calculations showed that the sample had enough power for observed ORs.

\section{CONCLUSION}

Several maternal risk factors of IUGR were identified. Awareness of these predictors, not only helps in proper preventive care but also helps in prompt diagnosis of IUGR. Nutritional intervention could help increase maternal weight during pregnancy. Screening and proper management of GDM and PIH would help in reduction of incidence of IUGR in the community which would eventually help in succeeding the goal of reduced neonatal mortality and morbidity.

\section{REFERENCES}

1. Zeitlin J. Impact of fetal growth restriction on mortality and morbidity in a very preterm birth cohort. $J$ Pediatr 2010; 157:733-9.

2. Turan OM. Duration of persistent abnormal ductus venosus flow and its impact on perinatal outcome in fetal growth restriction. Ultrasound Obstet Gynecol 2011; 38:295-302.

3. Narang A, Reddy R. Prematurity and intrauterine growth retardation. In: Bhat SR, editor. Achars text book of pediatrics. 4th ed. India: Universities press; 2009:184.

4. Kleijer ME, Dekker GA, Heard AR. Risk factors for intrauterine growth restriction in a socio-economically disadvantaged region. J Matern Fetal Neonatal Med 2005; 18:23-30.

5. Zafar H. Frequency of IUGR in pregnancy induced hypertension. JUMDC 2012; 3:8.

6. Murki S, Sharma D. Intrauterine growth restriction - A review article. J Neonatal Biol 2014; 3:135.

7. Jamal $M$, Khan $N$. Maternal factors associated with low birth weight. J Coll Physicians Surg Pak 2003; 13:25-8.

8. Muhammad T, Khattak AA, Rehman S, Khan MA, Khan A, Khan M. Maternal factors associated with intrauterine growth restriction. J Ayub Med Coll Abbottabad 2010; 22:64-9.

9. Odibo AO, Nelson D, Stamilio DM, Sehdev HM, Macones GA. Advanced maternal age is an independent risk factor for intrauterine growth restriction. Am J Perinatol 2006; 23:325-8.

10. Anjum F, Javed T, Afzal M, Sheikh G. Maternal risk factors associated with low birth weight: A case control study. ANNALS 2011; 17:223-8.

11. Motghare DD, Vaz FS, Pawaskar AM, Kulkarni MS. Maternal determinants of intrauterine growth restriction in Goa, India: A case- control study. Glob J Med Public Health 2014; 3:1-6.

12. Acharya D, Nagraj K, Nair NS, Bhat HV. Maternal determinants of intrauterine growth retardation: A case control study in Udupi District, Karnataka. Indian J Community Med 2004; 29:4.

13. DAS TR, Jahan S, Begum SR, Low birth weight and associated maternal factors. J Bangladesh Coll Phys Surg 2003; 21:52-6.

14. Husely TC, Neal D, Bondo SC, Husely T, Newman R. Maternal pre-pregnant body mass index and weight gain related to low birth weight in South Carolina. South Med J 2005; 98:411-5. 
15. Muthayya S. Maternal nutrition \& low birth weight - what is really important? Review article. Indian J Med Res 2009; 130: 600-8.

16. Sharma M, Mishra S. Maternal risk factors and consequences of low birth weight in infants. IOSR- JHSS 2013; 13:39-45.

17. World Health Organization. Maternal anthropometry and pregnancy outcomes: a WHO collaborative study. Bull World Health Organ 1995; 73(Suppl):1-98.

18. Naidu AN, Rao NP. Body mass index: a measure of the nutritional status in Indian populations. Eur J Clin Nutr 1994; 48: $131-40$.

19. Muthayya S. Maternal vitamin B12 status is a determinant of intrauterine growth retardation in South Indians. Eur J Clin Nutr 2006; 60:791-801.

20. Abrams B, Selvin S. Maternal weight gain pattern and birth weight. Obstet Gynecol 1995; 86:163-9.
21. Callava EO. Intrauterine growth restriction: Recognizing the risk factors, 2011. www.obgyn.net/articles/intrauterine-growthrestriction-recognizing-risk-factors.

22. Prada JA, Tsang RC. Biological mechanisms of environmentally induced causes of IUGR. Eur J Clin Nutr 1998; 52:21-7.

23. Thompson JMD. Risk factors for small-for-gestational-age babies: The Auckland birth weight collaborative study. J Paediatr Child Health 2001; 37:369-75.

24. Burke N. Influence of maternal risk factors on perinatal outcomes in IUGR: analysis of the national multicenter prospective PORTO study. AJOG 2014; 210:93.

25. Villar J. Preeclampsia, gestational hypertension and intrauterine growth restriction, related or independent conditions? Am J Obstetr Gynecol 2006; 194:921-31.

26. Aghamolaei IT, Eftekhar H, Zare S. Risk factors associated with intrauterine growth retardation (IUGR) in Bandar Abbas. J Med Sci 2007; 7:665-9. 